\title{
Standards, Inequality in Education and Efficiency
}

\author{
Şevket Alper Koç ${ }^{1,2}$, Hakkı Cenk Erkin ${ }^{1}$ \\ Received: 17/11/2014; Revised: 24/01/2015; Accepted: 28/01/2015
}

\begin{abstract}
We develop a model of educational standards that includes inequality in educational opportunities. Our model shows that policymakers setting an output maximizing standard need to consider structural factors such as inequality of income and opportunity, skill mismatch in the economy, profit and wage shares and labor market imperfections. High standards are not optimal under severe educational inequality; they lead to lower output when many cannot access quality education. Optimal standard rises along with increasing opportunities for poor students. Targeted subsidies enhance both distributional and efficiency-related objectives. Other effective policies to extend skilled labor and to improve poor workers' income are remedying information problems between employers and workers and distributing more of output gains toward labor.
\end{abstract}

Keywords: Education and Inequality, Government Policy, Human Capital, skills, Occupational Choice, Labor Productivity

JEL Codes: I24, I28, J24

\footnotetext{
${ }^{1}$ Department of Economics, Kocaeli University, Kocaeli, Turkey

${ }^{2}$ Corresponding Author, email: sevketkoc@hotmail.com
} 


\section{Introduction}

Human capital is an important input into production process. Educational standards, by setting minimum levels of knowledge and skills to be acquired at school, influence students' human capital accumulation decisions. Standards can change stock of human capital in the economy, and in turn, levels of aggregate output and income. In labor markets where asymmetric information between employers and workers create suboptimal outcomes, standards can provide incentives for workers to accumulate more capital. They can contribute to economic growth by raising education quality (Hanushek and Woessman, 2007). Standards, however, can also have an adverse effect on income distribution by excluding some workers from higher paying jobs.

There have been studies linking inequality to adverse economic outcomes, slower growth being one of them (Easterly, 2007; Berg and Ostry, 2011). Another line of research, summarized below, sought to uncover effects of educational standards on welfare and output. The idea that certain policy objectives may define an optimal level of standard is put forward. This study is inspired by the two lines of research. We argue that, in line with previous research, an optimal educational standard exists given policy objectives and structure of the economy. We show that opportunity inequality in education might significantly limit the positive effect on output of a standard even when the policy concern is only productive efficiency. Other structural variables such as labor productivity and wage share, skill mismatch, imperfect information in labor markets and income inequality should also be taken into account in setting the optimal standard.

The second section summarizes the previous work that have inspired our model. The third section presents the model and the fourth section discusses the results. Section 5 concludes.

\section{Literature Review}

Human capital theory, despite being the leading explanation of linkages between schooling and economic returns, has little to say on standards. It has been widely assumed that education enhances productivity almost automatically once it's aligned with needs of the economy. As a result there are few studies focused on educational process or on students' decision of how much effort to devote to learning. However, effective learning only takes place if students are active participants at school. Given ability, student time and effort are among the most important inputs to education (Bishop, 2004). The level of a worker's human capital is only partially explained by her years of schooling; another factor as important is how effective she has acquired skills during this period. Moreover, students' calculations of returns to studying can be significantly altered if job applicants have difficulty in presenting their skills in the labor market. When employers cannot perfectly observe worker productivity, a student's success or failure to pass a standard or to earn a qualification that is intended to certify her effort at school might have a major impact on her future earnings.

Information asymmetry in a market where goods are differentiated in terms of quality creates the need for sorting. If buyers cannot observe the quality of a good before purchasing it, the market price will reflect average quality. Average quality of goods on sale and the market price can keep falling as owners of high quality goods who have higher reservation prices withdraw from the market (Akerlof, 1970). The implications for the labor market would be a low average wage, more skilled workers stopping job search, and employment of only less productive workers as long as employers cannot differentiate between them. This is in contrast with the observations because better workers can signal their quality, employers can screen applicants and firms learn about the true potential of their employees over time. Spence (1973) modeled the role of signaling in transmitting the characteristics of an individual in the labor market. More productive workers can try to signal their quality to firms by undertaking a costly 
activity such as higher education, which is hard to imitate by less productive workers. Educational standards can act as strong signals for individual productivity. In imperfect labor markets where workers are better informed about their productivity, employers view workers' certifications as sources of information about their ability and effort; they judge an applicant's productivity potential compared to other applicants' by her rank in the educational assessment system.

The linkages between student learning, standards and earnings have inspired theoretical work that has sought explanations based on student motivation and effort. Costrell (1994) made the first attempt to provide a theoretical explanation of educational standards. In Costrell's model where a worker's productivity depends on her effort during school years, a policy maker sets an educational standard and in response utility maximizing students choose whether to meet the standard. An increase in the standard raises labor market earnings for those students who provide more effort to meet the standard while leaving the earnings of those who fail to meet the standard unchanged. An egalitarian policy maker chooses lower standards and raises the graduation rate to keep income distribution less unequal but at the cost of lower potential output. Therefore, a policy maker's choice of an educational standard involves a trade-off between income equality and level of income.

Betts (1998) reaches a different conclusion by taking into account differences in student ability. The trade-off between equality and income disappears as an egalitarian policy maker might prefer higher standards than a policy maker whose goal is to maximize total income. In the equilibrium, students above a threshold ability level provide more effort to meet the standard while students below the threshold, unable to meet the standard, exert minimum effort. Each group is rewarded in the labor market according to their average ability and observed effort level. An increase in the standard makes both groups better off. Fewer individuals pass the standard but their effort and average ability is higher and so is their wage. Those failing the standard now includes some relatively more able individuals who would have met the old standard. Therefore, earnings of this group also increase along with its average ability. The only group experiencing lower wages are those who would have passed the standard before but now fail to meet the higher level.

Costrell and Betts both assumed that labor markets operated under the assumptions of perfect competition. De Paola and Scoppa (2007) include into the analysis labor market imperfections that cause a divergence between wages and marginal product of workers. In such distorted labor markets where workers earn less than their productivity, students will have less incentive to study hard. A policy maker can counter this disincentive and raise student effort by using educational standards. They find that a policy maker maximizing total output should set a lower standard in more distorted labor markets. In a separate paper (De Paola and Scoppa, 2010), they analyze the merits and shortcomings of different standards, centralized and decentralized evaluation systems. A centralized evaluation system induces student to study harder because, being more precise, it provides a better signal of students' skills to employers. On the other hand, if significant measurement errors are probable during evaluation, then a decentralized system with frequent evaluations will provide a more accurate representation of student ability and performance. De Carvalho Andrade and De Castro (2011) also point to a possible adverse outcome due to measurement problems: an increase in the testing standard may reduce the average productivity of the selected group. If the exam does not verify all skills, especially those most relevant for employers, then skills necessary to succeed in the test, but less related to workplace success, will be emphasized at the expense of productivity enhancing skills.

De Fraja Oliveira and Zanchi (2010) build a theoretical model where students' achievement is determined by the combined effort put in the educational process by students, their parents 
and schools. Although all three actors value student achievement, each has a different cost function associated with own effort spent, hence their interests are not totally harmonious. In the equilibrium of the model, students', parents' and school's efforts on student achievement can be complements or substitutes depending on the parameters. For example, a school's improvement of its education would lead to lower effort by its students when students' and school's efforts are substitutes. Their accompanying empirical analysis finds that students' or parents' more effort leads the other party to exert more effort. Increasing school effort induces more effort from parents but not from students.

In education economics literature, higher standards (tougher grading practices, minimum graduation requirements, centralized and standardized exams, etc.) are usually found to increase student achievement, although the outcomes are unevenly divided between different groups, and not all effects are positive. Bishop (2005) studies three types of high school exit exams to qualify for high school diploma, voluntary curriculum-based external exit exams, universal curriculum-based external exit exams and minimum competency tests. The nations and the provinces within a specific country that use universal curriculum-based external exams have higher student achievement. Backes-Gellner and Veen (2006) also find support for central external exit exams. In Germany, graduates of high schools located in states requiring central exit exams to get a high school diploma earn a wage premium over those high school graduates coming from states where each school designs and conducts its own exit exam.

Bonesronning (2004) assumes that teachers can have an effect on student effort, and thus student achievement, by setting grading standards. His empirical analysis for Norway shows students who are graded with a tougher standard in the lower secondary school perform significantly better than other students in terms of standardized mathematics tests. Figlio and Lucas (2004) also find that high grading standards increase student test performance in mathematics and reading in elementary school. However, the effect is more pronounced for high-ability students.

Betts and Grogger (2003) find mixed evidence on the effects of higher grading standards. Although high standards in high school raise average student achievement in terms of test scores, the improvement comes mainly from already successful students. Tougher standards do not increase high school graduation or college attendance rates.

Inequality in various forms limits learning opportunities for disadvantaged children as they proceed through the education system. It is not only ability that makes the difference; socioeconomic variables such as family income, parental education or school quality in the neighborhood are all important factors influencing a students' educational achievement (Williams Shanks and Robinson, 2013). Studies carried out in different countries show that family background and neighborhood characteristics explain $40-65 \%$ of variation in years of schooling between individuals (Björklund and Salvanes, 2011). The correlation between parents' education and their children's is between 0.30 and 0.50 . As stated by Heckman (2008), "the accident of birth is a major source of inequality"; about half of the inequality in the present value of lifetime earnings can be traced to factors determined before an individual is 18 years old.

Along with worsening income inequality, the role of family income in determining educational success seems to be increasing: the gap in standardized test scores between high and low-income American families is roughly 30 to $40 \%$ larger compared to twenty-five years earlier (Reardon, 2011). The imbalance between rich and poor children in college graduation has grown by half since 1980s (Baily and Dynarski, 2011). Kornrich and Furstenberg (2013) report that high-income families are spending nine times as much per child as low-income 
families. The ratio was five to one in 1970s. Since then spending by well-off families more than doubled, while spending by low-income families grew by only $20 \%$.

Children of affluent families have the means to attend high quality schools either by paying tuition if it is a private school or by relocating to a neighborhood that has a good public school. They also have the opportunity to attend private test preparation centers or to get private tutoring which have a positive effect on test scores (Guimaraes and Sampaio, 2013). Low income families usually face credit constraints; poor parents' inability to borrow against their children's future income might have a large impact on the inefficient accumulation of human capital, especially if they cause underinvestment in early childhood education (Lochner and Monge-Naranjo, 2011).

Students coming from disadvantaged families have a lower probability to attend university (Giorgio and Checchi, 2007), a higher probability of dropping-out once enrolled (Niu and Tienda, 2013), and lower earnings expectations after graduation (Delaney, Harmon and Redmond, 2011).

\section{Model}

We conceptualize inequality of opportunity in education in a simple way. Some families are assumed to lack resources to spend enough for their children's education. They are also likely to face credit constraints so they cannot borrow long term to finance education. The "poor" group's proportion in the population is $\alpha(0<\alpha<1)$. The rest, $(1-\alpha)$, are better off or "rich" in the sense that they can spend considerably more for education. The population is normalized to 1. For simplicity, we assume each family within a group spends the same amount on education, and this amount for the poor is less than the amount spent by the rich. Educational expenditure increases quality of learning over a basic level supplied by an average public school. Education at public schools of basic quality is free. Unfortunately, most public schools provide an unsatisfactory education; their graduates ultimately fail to attend selective high schools or university and end up in low-skill jobs in Turkey. Access to better education over the basic level costs money, and educational spending can take many different forms. Families can incur additional costs in terms of higher rents or house prices by moving to neighborhoods with good public schools. Parents make considerable "donations" to enroll their children to one these schools or to choose a specific teacher with a good reputation. Better-off families can also afford cost of a private school, which was about half of the mean annual family income in 2012 in Turkey. ${ }^{3}$ Families also spend on private tutoring and after-school support to improve their children's test performance. Other very important factors for academic success, educational environment at home and quality pre-school education require substantial financial investment. Therefore, we assume that money spent for education increases achievement at school, likelihood of passing educational standards and accumulation of human capital.

People live for two periods. In the first period, they are students; they obtain education and decide how much effort to spend for studying. During the time at school, they form human capital and increase their future productivity in relation to their studiousness, ability and money spent for their education. In the second period, they get a job and start working. There is no time discounting.

\footnotetext{
${ }^{3}$ Private schools and selective public schools at primary education excel in terms of test performance; their students are selected first into best high schools and then they go on to best colleges. The results (average score for a school) of the high school entrance exam in 2013 for İzmir, the third largest city in Turkey, show the pattern: out of 661 schools, 39 of 42 private schools are in the top 50. Of the top 5\% (top 33 schools), 31 are private. Reputed public schools are in the top 100 . It is also striking that at most $6 \%(42 / 661)$ of all students attend private schools.
} 
A student acquires academic skills (AS) at school according to the educational production function $A S=e a(1+v)$. Here $e$ is his effort and $a$ his ability; $e a$ is the academic accomplishment of a student with ability $a$ who exerts effort $e$ at a basic quality state school. $v$ shows to what extent money increases effectiveness of education over this basic level. Conceptualizing expenditure in this manner has an easy interpretation. For example, educational spending that is sufficient to produce a $v$ of 1 doubles the quality of education over the basic level. This approach requires the existence of a function that relates actual spending to the value of $v$. We assume that such a function exists and is increasing in the amount of money spent. A family spends $M$ and this is translated into better school performance according to the function $v(M)=l M^{k}$ where $M \geq 1,0<k<1$ and $0<l \leq 1$. Family expenditure on education is either $M_{r}$ or $M_{p}\left(M_{r}>M_{p}\right)$; a poor family/student is indexed by $p$ and a betteroff one by $r$. Money raises educational quality and increases school performance: $\partial A S_{i} / \partial M_{j}=$ $e_{i} a_{i} \frac{k l}{M_{j}^{1-k}}, j \in\{p, r\}$. Each unit of effort is more productive if either ability or spending is higher: $\partial A S_{i} / \partial e_{i}=a_{i}\left(1+v_{j}\right)$. Notice that since $k$ is less than 1 , there are decreasing returns to educational spending: increasing expenditure raises quality less and less; additional investment on education has almost no effect on school performance if spending for a student is already very high.

Academic skills determine whether a student passes a specific standard or not. The standard can be any instrument that measures student achievement such as graduation requirements, entrance or exit exams. We conceptualize the standard as a centralized university entrance exam because it is the most important assessment in relation to future earnings for a number of developing countries including Turkey. The standard in this model defines the minimum academic skills to pass the test and shows its difficulty or selectivity. In order not to complicate the analysis, we also assume that the test perfectly measures academic skills, and that all students passing the test are assumed to attend universities of the same quality and graduate with a university diploma of equal value.

If $A S=e a(1+v)$ is high enough to satisfy the standard, the student succeeds to attend university $(e a(1+v) \geq s)$. However, academic achievement is not exactly the same with human capital demand at work. There is inevitably some degree of mismatch between academic skills and job skills. Schooling not only prepares students for future jobs but has many private or social noneconomic benefits such as personal growth and awareness of civic duties and social responsibility. These skills are at best indirectly related to productivity at work. Moreover, academic education varies a great deal in its ability to equip students with relevant job skills across subjects. Human capital of a student, $H K_{i}=e_{i} a_{i}\left(1+n v_{j}\right)$, or his future productivity at work is assumed to be a proportion of his skills. Thus effective spending on education $(v)$ increases test preparedness more $\left(e_{i} a_{i}\right)$ than it increases job skills $\left(n e_{i} a_{i}\right)$ where $0<n<1$.

Student ability is distributed uniformly on $[\underline{a}, \bar{a}]$ for both poor and better-off families with density function $g(a)=1 /(\bar{a}-\underline{a})$. At any period there are some children having the same ability level $\tilde{a}$ : $\alpha$ of them are poor and $(1-\alpha)$ are better-off. Uniform distribution for ability is not realistic considering that distribution of intelligence is approximated by the bell curve, but it greatly simplifies the analysis and no major insight seems to be lost.

There are two types of jobs a student can get once he enters the labor market. Low-skilled jobs are those where ability and individual productivity are not important and employees earn a constant amount $w$. In contrast, an employee's ability and productivity is a significant determinant of his compensation in high-skilled jobs. Those jobs require more skills; to be offered a job in high-skilled sector, a worker must show that he has sufficient human capital by 
having passed the standard. Employees working at high-skilled jobs produce and earn more than employees in low-skilled sector. Their wage changes over time: there are two sub-periods in for workers in this sector. During the early period at work, employers cannot observe employees' productivity and, thus pay all of them the same wage $B(s)$, where $s$ is the level of the standard $\left(B(s)^{\prime}>0, B(s)^{\prime \prime} \leq 0\right)$. In time, employers begin to know their employees enough so that they can guess correctly each one's individual productivity. During this period, a worker gets a share of his product $(\pi+\rho) e a(1+n v)$. In essence, a worker's product is a multiple of his human capital, $e a(1+n v)$. He gets a share of it, $\pi e a(1+n v)$, and the rest, capital share or profit, $\rho e a(1+n v)$ goes to the employer. We assume that $\pi>0, \rho \geq 0$ and $\pi+\rho \geq 1$. The length of the period when individual productivity is observable is represented by $\beta$ as a proportion of a high-skilled employee's working life. $\beta$ is a measure of the degree of informational problems in the labor market; it falls as the information asymmetry gets worse. The lifetime wage earnings of a high-skilled worker is $(1-\beta) B(s)+\beta \pi e a(1+n v)$. Profit per worker in the second sub-period is $\rho e a(1+n v)$ and the profit rate is $\rho /(\pi+\rho)$. Since workers produce the same but get $B(s)$ in the first sub-period, the total profit becomes $((1-\beta) \pi+\rho) e a(1+n v)-(1-\beta) B(s)$.

Product of a low-skilled worker is $\tau w$ where $(\tau-1) w$ is profit per worker; $(\tau-1) / \tau$ is profit rate for a firm in low-skill sector $(\tau \geq 1)$. Wage share in this sector is $1 / \tau$ and $\pi /(\pi+\rho)$ in the high-skill sector.

Labor market clears; there is no unemployment. It is imperfect in the sense that average wages in the high-skilled sector are below marginal product due to information asymmetry about worker productivity. Moreover, both sectors are open to international trade; thus there are no price or wage fluctuations due to changes in labor supply in either sector.

A student's utility function is given below. Studying requires time and effort and so entails a cost, $\gamma e^{2} / 2$, where $\gamma>0$. Cost is increasing faster than future consumption as effort is expended; the trade-off between leisure and consumption becomes less appealing for a student at higher levels of effort. A student whose academic accomplishment is not enough to pass the standard and earn a diploma, $e_{i}^{j} a_{i}^{j}\left(1+v_{j}\right)<s$, will be placed in a low-skill job and earn $w$. Since human capital is not required at low-skill jobs, he expends no effort and incurs no effort cost at school. Otherwise, he expends effort and accumulates human capital, works in the highskill sector and earns first $B(s)$, then $\pi e_{i}^{j} a_{i}^{j}\left(1+n v_{j}\right)$ once his productivity becomes visible.

$$
\begin{aligned}
& w, \quad e_{i}^{j} a_{i}^{j}\left(1+v_{j}\right)<s \\
& U_{i}^{j}=Y_{i}^{j}=(1) B(s)+\quad e_{i}^{j} a_{i}^{j}\left(1+n v_{j}\right) \frac{\left(e_{i}^{j}\right)^{2}}{2}, \quad e_{i}^{j} a_{i}^{j}\left(1+v_{j}\right) \quad s
\end{aligned}
$$

Solving a student's utility maximization problem requires determining the decision rules a la Betts (1998). There are two critical levels of ability, $a_{1}^{j}$ and $a_{2}^{j}$ for each group. Poor students with low ability and rich students with very low ability would rather exert no effort and work in a low-skill job rather than studying hard enough to pass the test; the effort cost of doing so would be too high. Students around average ability will study enough to pass the test so that they can earn higher wages although they would have spent less effort if the standard were lower. The first and the lower ability threshold differentiates these two groups.

Let $e_{i}^{*}$ be the effort level that is the solution for $Y_{i}^{j}$ and $\bar{e}_{i}$ be the effort level required to meet the standard for student $i$. Then $e_{i}^{*}=\frac{\beta \pi\left(1+n v_{j}\right) a_{i}}{\gamma}$ and $\bar{e}_{i}=\frac{s}{a_{i}\left(1+v_{j}\right)}$. For some students, 
$Y_{i}^{j}\left(e_{i}^{*}\right)$ can be greater than $w$, but $e_{i}^{*}$ can be smaller than $\bar{e}_{i}$. In fact for any student whose ability is less than the upper ability threshold $a_{2}^{j}, e_{i}^{*}<\bar{e}_{i} \cdot{ }^{4}$ Such a student's decision depends on whether $Y_{i}^{j}\left(\bar{e}_{i}\right)$ is greater than low-skill wage or not. Let student $i$ with $a_{i}^{j}=a_{1}^{j}$ be indifferent between not studying and having lifetime low-skill earnings $w$ and studying just enough to pass the test and having lifetime earnings $(1-\beta) B(s)+\beta \pi e_{i}^{j} a_{i}^{j}\left(1+n v_{j}\right)$. This student will study up to the point where his performance equals the standard, $e_{1}^{j} a_{1}^{j}\left(1+v_{j}\right)=s$, thus his optimal effort will be $e_{1}^{j}=\frac{s}{a_{1}^{j}\left(1+v_{j}\right)}$. His utility at either alternative is equal at $a_{i}^{j}=a_{1}^{j}$ :

$w=(1 \quad) B(s)+\quad e_{1}^{j} a_{1}^{j}\left(1+n v_{j}\right) \frac{\left(e_{1}^{j}\right)^{2}}{2}$

$w=(1 \quad) B(s)+\frac{s}{a_{1}^{j}\left(1+v_{j}\right)} a_{1}^{j}\left(1+n v_{j}\right) \frac{\left(\frac{s}{a_{1}^{j}\left(1+v_{j}\right)}\right)^{2}}{2}$

Solving the above equality for $a_{1}^{j}$ gives the first ability threshold:

$a_{1}^{j}=\sqrt{\left.\frac{2\left(1+v_{j}\right)\left[\left(1+v_{j}\right)((1) B(s) w)+\left(1+n v_{j}\right)\right.}{2}\right]^{S}}$

Any student with $a_{i}^{j}<a_{1}^{j}$ will have $Y_{i}^{j}\left(\bar{e}_{i}\right)<w$ and spend no effort. Students with $a_{i}^{j} \geq a_{1}^{j}$ prefer exerting $\bar{e}_{i}$ and passing the test. This threshold is lower for rich students so that a larger fraction of them can go to university $\left(\bar{a}-a_{1}^{r}>\bar{a}-a_{1}^{p}\right)$ because they can compensate the negative effect of lower ability on learning by buying higher quality education $\left(v_{r}>v_{p}\right)$. Better compensation in the high-skill sector encourages college attendance while rise in lowskill wage lowers it.

Optimal student effort falls as ability increases until $a_{i}^{j}=a_{2}^{j}$ because ability raises the effectiveness of learning and makes reaching the fixed standard easier. At $a_{i}^{j}=a_{2}^{j}$, there comes the point beyond which high ability students voluntarily provide more than required effort thanks to attractive future earnings $\left(e_{i}^{*} \geq \bar{e}_{i}\right)$. Therefore optimal effort for student $i$ without the standard will be equal to the level of his effort just enough to pass the standard: $e_{2}^{j}=$ $\frac{\beta \pi\left(1+n v_{j}\right) a_{2}^{j}}{\gamma}=\frac{s}{a_{2}^{j}\left(1+n v_{j}\right)}$. Solving for $a_{2}^{j}$ gives the second ability threshold

$a_{2}^{j}=\sqrt{\frac{s}{\left(1+v_{j}\right)\left(1+n v_{j}\right)}}$

\footnotetext{
${ }^{4}$ The proof is in Appendix A.
} 
The second threshold will again be lower for richer students. All students with $a_{i}^{j}>a_{2}^{j}$ exert more effort than the standard requires, and their optimal effort increases along with ability until $a_{i}^{j}=\bar{a}$. It is straightforward to show that $a_{1}^{j}<a_{2}^{j}{ }^{5}$

Given students' optimal decision rules, the objective of the policymaker needs to be defined to complete the model. We assume, as in De Paola and Scoppa, that the policymaker's main concern is boosting the potential output of the economy. Therefore the policy objective is maximizing a social welfare function (SWF) that is simply the net output. It is the difference between total output of the economy and total cost of effort.

$$
\begin{aligned}
& S W F=\overline{\bar{a}} \underline{\underline{a}}\left[\begin{array}{l}
\left.\int_{\underline{a}}^{a_{1}^{p}} w d a+\int_{a_{1}^{p}}^{a_{2}^{p}}\left[(+)\left[e_{1}^{p} a_{i}^{p}\left(1+n v_{p}\right)\right] \frac{\left(e_{1}^{p}\right)^{2}}{2}\right) d a\right] \\
\left.+\int_{a_{2}^{p}}^{\bar{a}}(1+)\left[e_{2}^{p} a_{i}^{p}\left(1+n v_{p}\right)\right] \frac{\left(e_{1}^{p}\right)^{2}}{2}\right) d a
\end{array}\right] \\
& +\frac{1}{\bar{a} \underline{\underline{a}}}\left[\begin{array}{l}
\int_{\underline{a}}^{a_{1}^{r}} w d a+\int_{a_{1}^{r}}^{a_{2}^{r}}\left((+)\left[e_{1}^{r} a_{i}^{r}\left(1+n v_{r}\right)\right] \frac{\left(e_{1}^{r}\right)^{2}}{2}\right) d a \\
\left.+\int_{a_{2}^{r}}^{\bar{a}}(1+)\left[e_{2}^{r} a_{i}^{r}\left(1+n v_{r}\right)\right] \frac{\left(e_{1}^{r}\right)^{2}}{2}\right) d a
\end{array}\right]
\end{aligned}
$$

((( The first term of SWF is the contribution to total net product by poor workers. The expression in the first squared brackets is net output produced by the poor and $\alpha$ is their share in the population. The first term in the squared bracket is the output (and, since they exert no effort at school, also net output) by poor workers who have no diploma and work in the lowskill sector. The second and third terms are, respectively, output by and cost of effort of those poor workers who exerted just enough effort to pass the standard. The difference of the second and third terms gives the net output by this group. Similarly, the fourth and fifth terms give output by and cost of effort of high ability poor workers who would have studied as hard even without the standard. Better-off workers' contribution to total net product is the second term of SWF and its parts can be explained similarly.

Substituting in $e_{1}^{j}=\frac{s}{a_{1}^{j}\left(1+v_{j}\right)}$ and $e_{2}^{j}=\frac{\beta \pi\left(1+n v_{j}\right) a_{2}^{j}}{\gamma}$, SWF can be written as

\footnotetext{
${ }^{5}$ The proof is in Appendix B.
} 


$$
\begin{aligned}
& S W F=\overline{\bar{a}} \underline{a}\left[\begin{array}{c}
w\left(a_{1}^{p} \frac{a}{)}\right)+(+)\left(\frac{s}{1+v_{p}}\right)\left(1+n v_{p}\right)\left(a_{2}^{p} a_{1}^{p}\right) \\
\left.+\left(\frac{s^{2}}{2\left(1+v_{p}\right)^{2}}\right)\left(\frac{1}{a_{2}^{p}} \frac{1}{a_{1}^{p}}\right)+\left(\frac{\left(1+n v_{p}\right)^{2}}{\left.\left(1-\frac{1}{2}\right)+p\right)\left(\frac{\bar{a}^{3}\left(a_{2}^{p}\right)^{3}}{3}\right)}\right)\right]
\end{array}\right. \\
& +\frac{1}{\bar{a} \quad \underline{a}}\left[\begin{array}{c}
w\left(a_{1}^{r} \underline{a}\right)+(+)\left(\frac{s}{1+v_{r}}\right)\left(1+n v_{r}\right)\left(a_{2}^{r} a_{1}^{r}\right) \\
\left.\left.+\left(\frac{s^{2}}{2\left(1+v_{r}\right)^{2}}\right)\left(\frac{1}{a_{2}^{r}} \frac{1}{a_{1}^{r}}\right)+\left(\frac{\left(1+n v_{r}\right)^{2}}{(1} \overline{2}\right)+p\right)\left(\frac{\left.\bar{a}^{3}\left(a_{2}^{r}\right)^{3}\right)}{3}\right)\right]
\end{array}\right.
\end{aligned}
$$

The policymaker chooses a standard $s$ to maximize output and sets $\partial S W F / \partial s$ equal to 0 :

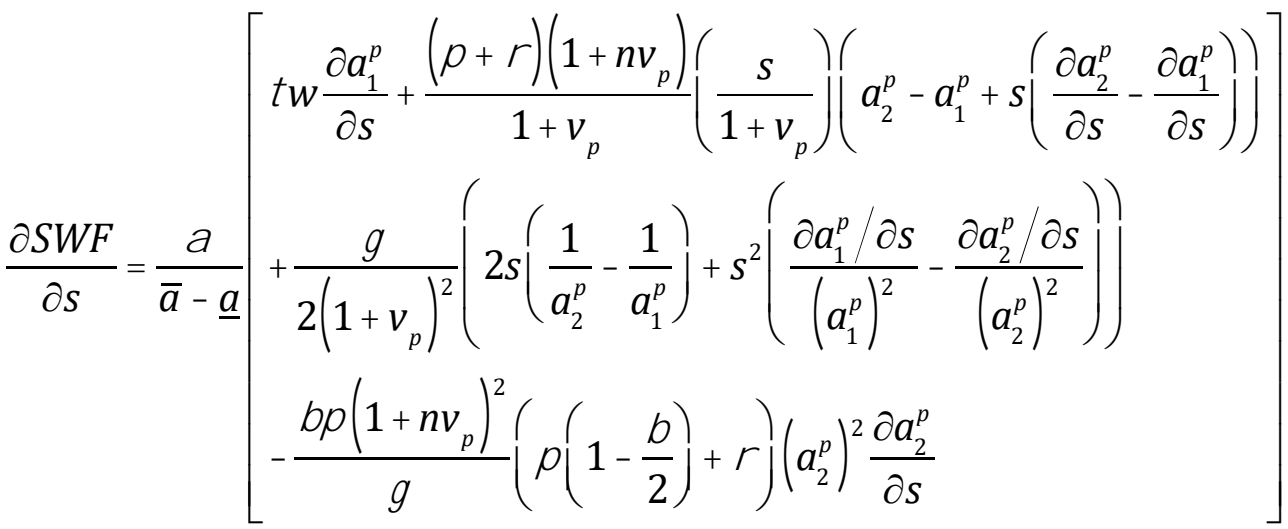

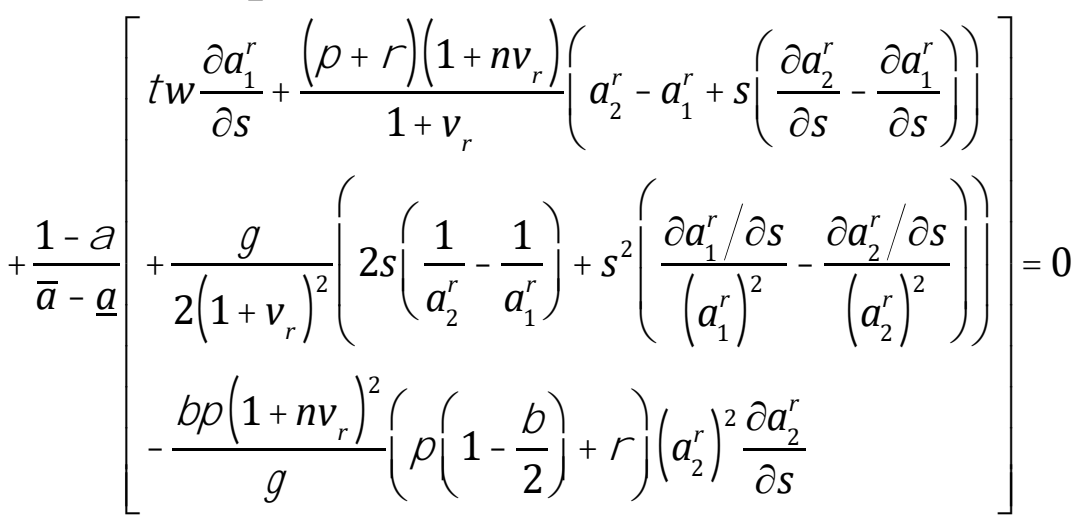

The optimal standard is the solution to the above equation. Due to the functional forms and long expressions, we cannot write either the standard or its partial derivatives explicitly even if $B(s)$ is defined algebraically. All analysis has to be carried out by simulations. ${ }^{6}$ Therefore, we tried to simplify the model so that analysis can be done more explicitly, especially about the key variables, even though simulation is still needed for measuring changes in output. As it turns out, the model can be simplified to a great extent with an assumption relating high-skill wage under information asymmetry, $B(s)$, to the length of that period, $(1-\beta)$, and low-skill wage, $w:(1-\beta) B(s)-w=0$ or $B(s)=\frac{w}{(1-\beta)}$.

\footnotetext{
${ }^{6}$ The simulation results of the full model will be made available upon request. The comparative static results from those simulations agree with the results of the simplified model.
} 
We have to assume that high-skill wage during the period when employers cannot observe workers' productivity is a multiple, the inverse of the length of that period, of low-skill wage. High-skill sector employers are willing to offer less to their new employees as information problem worsens (as $\beta$ decreases) because they have less time to compensate a job offer error such as offering a higher wage to a relatively low productivity worker. This assumption does not seem unreasonable as long as $\beta$ is not near to its extreme values of 0 or 1 . For example, if we assume that an employee's marginal product becomes observable to his employer during two thirds of his working life, $B$ will be three times the low-skill wage.

Under the simplifying assumption, ability threshold values change to $a_{1}^{j}=\sqrt{\frac{\gamma s}{2 \beta \pi\left(1+v_{j}\right)\left(1+n v_{j}\right)}}$ and $a_{2}^{j}=\sqrt{\frac{\gamma s}{\beta \pi\left(1+v_{j}\right)\left(1+n v_{j}\right)}}=\sqrt{2} a_{1}^{j}$. The social welfare function becomes

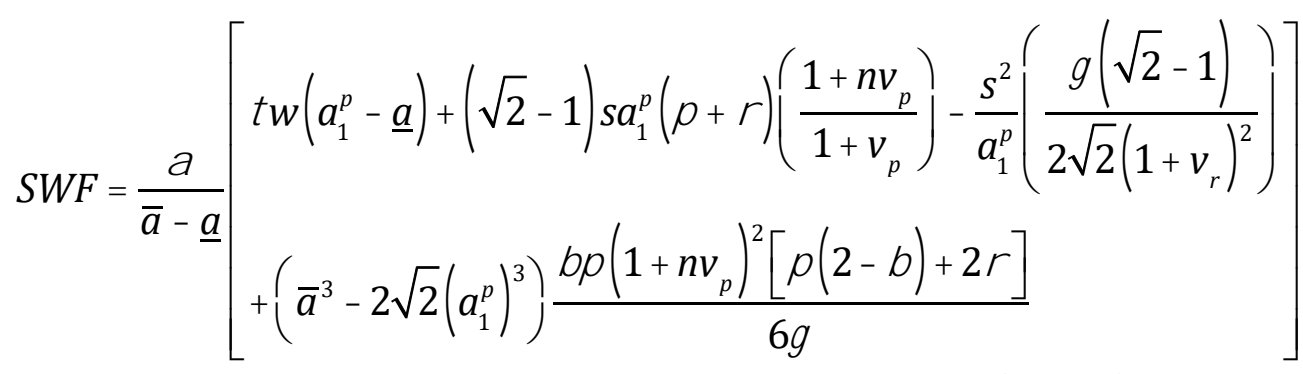

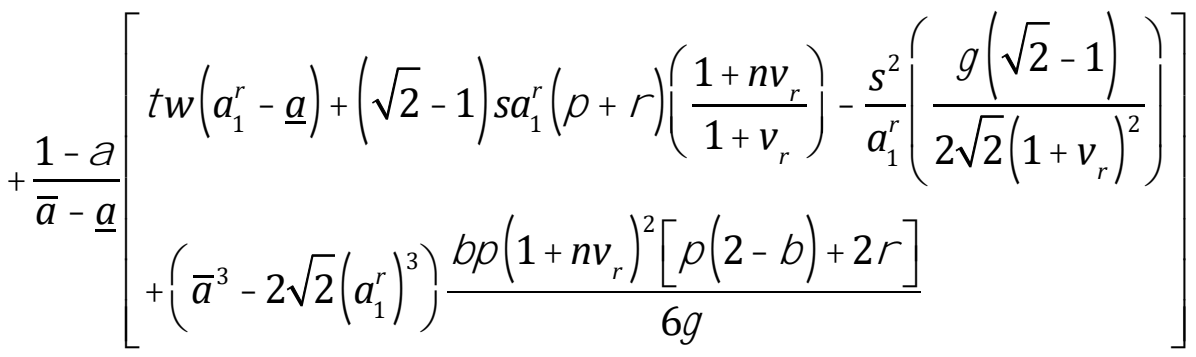

Noting that $\partial a_{1}^{p} / \partial s=a_{1}^{p} / 2 s$ and $\partial a_{1}^{r} / \partial s=a_{1}^{r} / 2 s$, the function is maximized when

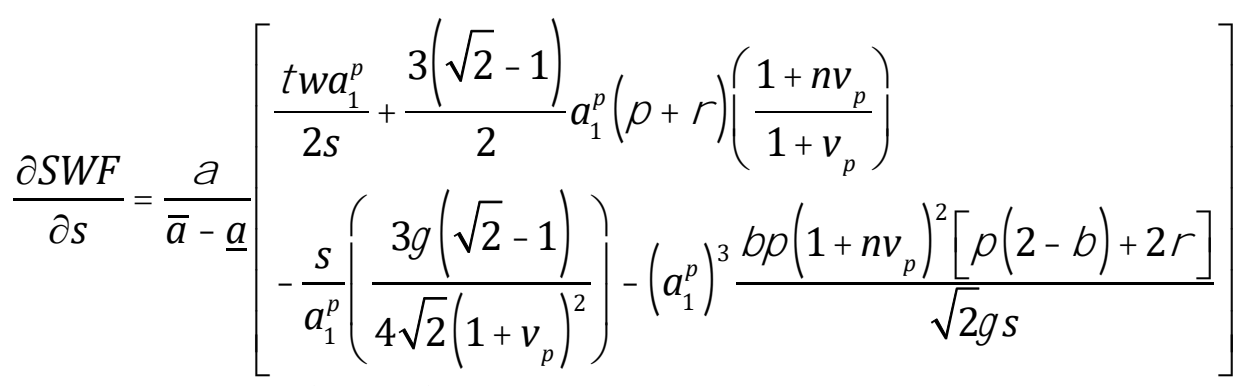

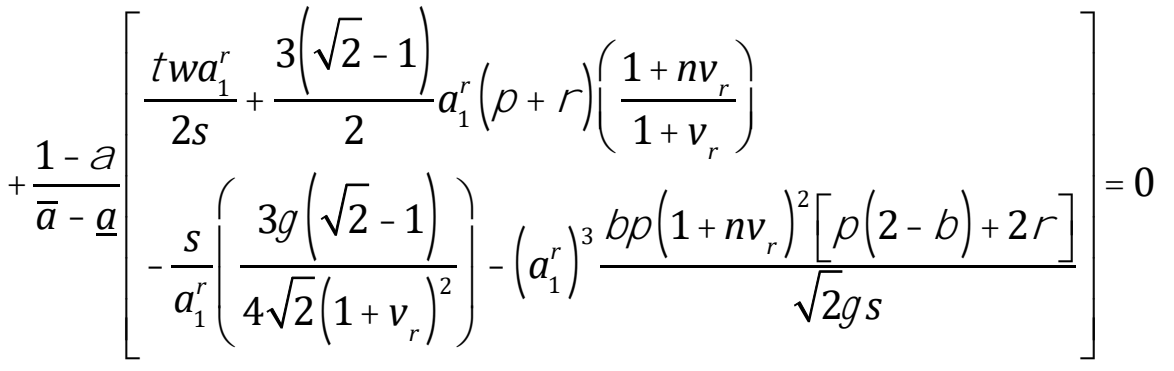

Now the optimal standard $s^{*}$ can be solved in terms of the parameters of the model: 


$$
S^{*}=\frac{\sqrt{2} w}{(3 \sqrt{2} 4)(++)}\left[\frac{\frac{\sqrt{\left(1+v_{p}\right)\left(1+n v_{p}\right)}}{\sqrt{\left(1+n v_{p}\right.}}+(1) \frac{1}{\sqrt{\left(1+v_{r}\right)\left(1+n v_{r}\right)}}}{\frac{\sqrt{1+n v_{r}}}{\left(1+v_{r}\right)^{3 / 2}}}\right]
$$

The optimal standard is a function of the low-skill sector productivity and wage, high-skill sector wage and profit shares, degree of information asymmetry, levels of educational spending, degree of mismatch between academic skills and job skills and income inequality in society. The bracketed expression shows the effect on the standard of differences in income and educational spending. Comparative static results are discussed in the next section. ${ }^{7}$

To confirm that SWF reaches its maximum value at $s^{*}$, we check the second derivative:

$$
\frac{\partial^{2} S W F}{\partial^{2} s}=\frac{1}{4 s(\bar{a} \quad \underline{a})}\left\{\begin{array}{c}
a_{1}^{p}\left[\frac{w}{s}+\left(\frac{3 \sqrt{2} 4}{\sqrt{2}}\right)\left(\frac{1+n v_{p}}{1+v_{p}}\right)(++)\right] \\
+(1) a_{1}^{r}\left[\frac{w}{s}+\left(\frac{3 \sqrt{2} 4}{\sqrt{2}}\right)\left(\frac{1+n v_{r}}{1+v_{r}}\right)(++)\right]
\end{array}\right\}
$$

Since the expression in the curly bracket is positive, $\frac{\partial^{2} S W F}{\partial s^{2}}$ is negative. Thus $S^{*}$ is the maximum point.

\section{Discussion of the results}

Educational standards increase student effort, human capital and output when worker productivity is imperfectly observable. There is no need for a standard in the case of perfect information. There would be no observation period, high-skill workers would always be paid proportional to their marginal product. All students above an ability threshold $\left(a_{i}^{j} \geq \frac{\sqrt{2 \gamma w}}{\pi\left(1+n v_{j}\right)}\right)$ would accumulate human capital in relation with their ability, and work in high-productivity sector. Others would provide no effort and take jobs in low-skill sector. ${ }^{8}$ Output, human capital accumulation and high-skilled employment would be higher than those under information asymmetry \& standards case. Simulation results can be seen in Table 1. ${ }^{9}$ Output and employment levels of the imperfect information cases are expressed as percentage of those of the perfect information case.

\footnotetext{
${ }^{7}$ Derivations of comparative statics are in Appendix C.

${ }^{8}$ See Appendix D.

${ }^{9}$ We assume that two thirds of students are poor, better-off families spend 6 times as much as poor families on education, half of academic knowledge turns into job skills, and productivity is not observable during the first $40 \%$ of a worker's career. Other assumed parameter values are the following: $M_{p}=0.25, M_{r}=1.5, l=1, k=$ $0.9, \pi=1.25, \rho=0.25, \tau=1.1, w=1, \underline{a}=0.5, \bar{a}=2.5, \gamma=1.5$.
} 
Table 1: Comparison with the perfect information case

\begin{tabular}{lcc}
\hline & Output & $\begin{array}{c}\text { Skilled } \\
\text { employment }\end{array}$ \\
\hline Perfect information case & 100 & 100 \\
Information asymmetry \& standard & 81.3 & 83.8 \\
Information asymmetry \& no standard & 77.7 & 77.9 \\
\hline
\end{tabular}

Values of these variables are even lower without a standard when employers are imperfectly informed. The ability threshold for high-skill employment rises considerably $\left(a_{i}^{j} \geq \frac{\sqrt{2 \gamma w}}{\pi\left(1+n v_{j}\right) \sqrt{\beta}}\right)$ depending on the extent of the information problem. ${ }^{10}$ Output and highskilled employment is $22 \%$ lower than the ideal case. Introducing a standard to the education system increases high-skill employment by $7.6 \%$ and raises output by $4.6 \%$.

Given the need for a standard under information asymmetry, we can turn to the analysis of effects of structural variables on the level of the standard. Our main concern, the relationship between education inequality, standard and output, will be discussed last.

First, it should be noted that a change in the standard creates two opposing effects on output. A rise in the standard, on the one hand, increases effort of those students between $a_{1}$ and $a_{2}$ $\left(\Delta e_{i}^{j}=\frac{\Delta s}{a_{i}\left(1+v_{j}\right)}>0\right)$; they study more to meet a higher standard and become more productive and better-paid workers. On the other hand, it decreases labor supply to high-skill sector by raising $a_{1}\left(\Delta a_{1}^{j}=\sqrt{\frac{\gamma}{8 \beta \pi\left(1+v_{j}\right)\left(1+n v_{j}\right) s}} \Delta s>0\right)$; higher standard discourages more students from studying. This result supports the trade-off between equity and efficiency stated by Costrell.

Decreasing information asymmetry increases student incentive to exert more effort; therefore, it lowers the optimal standard $\left(\frac{\partial s^{*}}{\partial \beta}<0\right)$ and raises output. As employers better observe their workers' skills, workers' earnings reflect their productivity closer, and they enjoy higher wages for a longer period. They reap more of the benefit of being a high productivity worker. This increases their incentive to provide effort and accumulate more human capital at school as reward for each unit of effort increases by $\pi a_{i}\left(1+n v_{j}\right) \Delta \beta$. Output can be further increased by lowering the standard and increasing the stock of high-skilled labor because rise in $\beta$ has no first-hand negative effect on effort for students between $a_{1}$ and $a_{2}$ unlike the case of educational spending which is explained below. Here the net change in output as a result of a lower standard is positive as the effect of larger skilled-labor supply dominates the loss of effort from workers between $\mathrm{a}_{1}$ and $\mathrm{a}_{2}$. The effect of $\beta$ on the standard falls gradually as the problem of information asymmetry decreases $\left(\frac{\partial^{2} s^{*}}{\partial \beta^{2}}>0\right)$. In the simulation, an increase in $\beta$ increases the output and the incomes of both group of workers. Profits also rise though to a lesser extent.

An increase in $(\pi+\rho)$ can be seen as a rise in labor productivity due to technology; as a result a high-skilled worker produces more output given effort. If the increase in productivity is appropriated by wages, only $\pi$ rises; in the opposite case it is a reward only for employers. A rise in $\pi$ has an effect on the standard similar to that of $\beta$. It increases students' incentive to study, reward for effort rises by $\left.\beta a\left(1+n v_{j}\right) \Delta \pi\right)$, enough so that net output increases with the

\footnotetext{
${ }^{10}$ See Appendix D.
} 
falling standard $\left(\frac{\partial s^{*}}{\partial \pi}<0\right)$. Rise in output is higher as more of a productivity increase is appropriated by labor $\left(\left|\frac{\partial s^{*}}{\partial \pi}\right|>\left|\frac{\partial s^{*}}{\partial \rho}\right|\right)$. In such a case, profits also rise together with workers' net income because during the period when skills are unobservable, employers earn more and pay almost the same fixed wage. Although a productivity increase appropriated by profits also lowers the optimal standard $\left(\frac{\partial s^{*}}{\partial \rho}<0\right)$ and increases output, its effect on either is weaker. It can be also the case where wage or profit share changes at the expense of the other when there is no change in $(\pi+\rho)$. In such a case, if wage share increases, workers will be more motivated to increase their human capital and so their incomes and net output will rise while profits fall. The opposite results are obtained when profit share increases.

A rise in low-skill wage discourages more students near the lower ability threshold from exerting effort at school; they would have studied to be in high-skill sector if low-skill wage had not increased. Maybe one would expect that the optimal standard has to fall to prevent this from happening, but actually the opposite result holds $\left(\frac{\partial s^{*}}{\partial w}>0\right)$. A rise in the standard causes more students at the previous lower threshold exert zero effort, but it increases the effort of many more students who are around or above the middle of the ability range. In the simulation, especially poor workers' income rises as a result of rising low-skill wage; profits fall and there is a small increase in output.

As $n$ increases, more of what is taught at school can be turned into productivity at work. This rises students' future wages in the high-skill sector, they become more willing to study. The effect of skilled-labor expansion is larger than the effort loss effect similar to the cases of a rise in $\beta$ or $\pi$; therefore, the optimal standard falls in response to a rise in compatibility between academic knowledge and job skills $\left(\frac{\partial s^{*}}{\partial n}<0\right)$.

Output maximizing standard has to be set at a lower level as the ratio of poor families, $\alpha$, rises in society $\left(\frac{\partial s^{*}}{\partial \alpha}<0\right)$. As income inequality increases, more students from poor families cannot pass the test so labor supply to the high-skill sector shrinks. The policymaker lowers the standard to counter this effect and to mitigate the fall in output. Workers' income and profits fall as well.

Educational inequality has undesirable consequences even when the only economic objective of education policy is to maximize net output. Here inequality of opportunity can be represented by difference in educational spending $\left(M_{r}-M_{p}\right)$ or in effectiveness of education $\left(v_{r}-v_{p}\right)$; it hinders growth when $M_{p}$ or $v_{p}$ is too low so that some able students get discouraged by poor quality education from investing in human capital. Falling educational spending by the poor decreases university attendance and high-skilled labor supply more than a similar expenditure fall for rich families $\left(\frac{\partial a_{1}^{p}}{\partial M_{p}}<0,\left|\frac{\partial a_{1}^{p}}{\partial M_{p}}\right|>\left|\frac{\partial a_{1}^{r}}{\partial M_{r}}\right|\right)$.

Inequality, besides denying high productivity jobs to some poor students, also causes output loss via another channel: high ability poor students $\left(a_{i}^{p} \in\left[a_{2}^{p}, \bar{a}\right]\right)$ spend less effort, accumulate less human capital and produce less output compared to similar rich students due to the disincentive of low quality education. Better education received by high ability rich students bolsters the marginal return to effort by $\left(1+n v_{r}\right)$ while this effect on poor students' return is smaller $\left(1+n v_{p}\right)$. As a result, poor students have lower reward per unit of effort, $\beta \pi a\left(1+n v_{p}\right)$, compared to similar rich students, $\beta \pi a\left(1+n v_{r}\right)$. 
In order to get the same return, poor students need to study more than rich students similar in ability. A poor student who pass the standard and has ability $a_{i}$ in the interval $\left[a_{1}^{p}, a_{2}^{p}\right]$ has to spend more effort compared to a similar rich student $\left(e_{i}^{p}=\frac{s}{a_{i}\left(1+v_{p}\right)}>e_{i}^{r}=\frac{s}{a_{i}\left(1+v_{r}\right)}\right)$. His human capital is larger $\left(s \frac{1+n v_{p}}{1+v_{p}}>s \frac{1+n v_{r}}{1+v_{r}}\right)$ and he produces more output $\left((\pi+\rho) s \frac{1+n v_{p}}{1+v_{p}}>\right.$ $\left.(\pi+\rho) s \frac{1+n v_{r}}{1+v_{r}}\right)$. These are also true when we compare group outcomes between $\left[a_{1}^{\square}, a_{2}^{p}\right]$ and $\left[a_{1}^{r}, a_{2}^{r}\right] .^{11}$

More educational spending by either income group raises both the optimal standard and labor supply to high productivity sector ${ }^{12}$ but the effect is much stronger when opportunity gap becomes smaller, i.e. poor students are supported. Higher spending by group $j$ also lowers the second threshold $a_{2}^{j}$, thus there is an increase in the number of students providing more effort than necessary. Both effects boost output. More effective education as a result of higher spending encourages some students near the lower threshold $a_{1}^{j}$ to study enough to satisfy the standard, who otherwise would have chosen not to study at all. It also increases high ability $\left(a_{i}^{j} \geq a_{2}^{j}\right)$ students' incentive to study: reward for each unit of effort rises by $\beta \pi a n \Delta v_{j}$. However, students between $a_{1}^{j}$ and $a_{2}^{j}$ in general have to study less now by almost $\frac{e_{i} \Delta v_{j}}{\left(1+v_{j}+\Delta v_{j}\right)}$ to pass the test. ${ }^{13}$ Additional expenditure on education, by raising its quality, makes studying time more productive; a student needs to spend less time studying to reach a fixed target. Therefore, although more students would gain access to university, those who want to study just enough to reach the standard would spend less effort. In response to higher spending, the policymaker has to increase the standard to lessen the fall in overall effort.

A similar amount of additional spending raises the standard more if it is allocated to poor students. Poor students between $a_{1}^{p}$ and $a_{2}^{p}$ have higher ability and spend more effort than comparable rich students, thus a rise in education quality substitutes more of their effort. When their studying time becomes more productive, they have to exert even less effort than comparable rich students to pass the test. Increase in output is also higher when quality of education for poor students improve. Simulation results show that a $10 \%$ increase in spending

${ }^{11}$ Total effort of such poor students, $\int_{a_{1}^{p}}^{a_{2}^{p}} \frac{s}{a_{i}^{p}\left(1+v_{p}\right)}=\frac{s}{\left(1+v_{p}\right)} \ln \left(a_{2}^{p}-a_{1}^{p}\right)=\frac{s}{\left(1+v_{p}\right)} \ln \left((\sqrt{2}-1) \square \square_{1}^{p}\right)$, is greater than that of similar rich students, $\frac{s}{\left(1+v_{r}\right)} \ln \left((\sqrt{2}-1) a_{1}^{r}\right)$. The same result also holds for human capital: $\int_{a_{1}^{p}}^{a_{2}^{p}} \frac{s\left(1+n v_{p}\right)}{\left(1+v_{p}\right)}=\frac{s\left(1+n v_{p}\right)}{\left(1+v_{p}\right)}\left(a_{2}^{p}-a_{1}^{p}\right)=\frac{s\left(1+n v_{p}\right)}{\left(1+v_{p}\right)}(\sqrt{2}-1) a_{1}^{p}$ versus $\frac{s\left(1+n v_{r}\right)}{\left(1+v_{r}\right)}(\sqrt{2}-1) a_{1}^{r}$.

${ }^{12}$ However, there is a point. For example, more spending for the poor lowers $a_{1}^{p}$ and $a_{2}^{p}$, but since it raises the standard, it also raises $a_{1}^{r}$ and $a_{2}^{r}$, causing a small drop in the number of rich students passing the standard $\left(\frac{\partial a_{1}^{p}}{\partial v_{p}}<0, \frac{\partial a_{1}^{r}}{\partial v_{p}}>0, \frac{\partial a_{2}^{p}}{\partial v_{p}}<0, \frac{\partial a_{2}^{r}}{\partial v_{p}}>0\right)$. Simulations show that net effect is a rise in skilled-labor supply, thus output increases. There is a similar effect on labor supply and output if rich spend more on education, but it is much smaller. Moreover, at very high levels of educational inequality, more spending by the rich lowers the standard.

${ }^{13}$ A student $a_{i}$ between $a_{1}^{j}$ and $a_{2}^{j}$ puts in effort $e_{i}=\frac{s}{a_{i}\left(1+v_{j}\right)}$. Subsidy to this group increases $v_{j}$ by $\Delta v_{j}$. Now the same student has to study by $e_{i}-\Delta e=\frac{s+\Delta s}{a_{i}\left(1+v_{j}+\Delta v_{j}\right)}$ to pass the test. Assume that $\Delta v_{j}$ is small enough that the change in the standard $(\Delta s)$ is negligible. Then the change in effort as a result of the subsidy is $\Delta e=\frac{s}{a_{i}\left(1+v_{j}\right)}-$ $\frac{s}{a_{i}\left(1+v_{j}+\Delta v_{j}\right)}$. This is equal to $\frac{s \Delta v_{j}}{a_{i}\left(1+v_{j}\right)\left(1+v_{j}+\Delta v_{j}\right)}$ or $\frac{e_{i} a_{i}\left(1+v_{j}\right) \Delta v_{j}}{a_{i}\left(1+v_{j}\right)\left(1+v_{j}+\Delta v_{j}\right)}=\frac{e_{i} \Delta v_{j}}{\left(1+v_{j}+\Delta v_{j}\right)}$. 
by the rich raises the standard and output by $0.1 \%$ and $3.8 \%$, respectively. If the same additional amount is spent for poor students, the standard rises by $4.1 \%$ and output by $5 \%$.

Table 2 shows the simulation results in terms of changes in the standard, high-skilled labor supply and output for different levels of education inequality. The initial level of inequality is the case where the rich spend 6 times as much as the poor do and get an education quality almost 2.5 times the base quality. Expenditure for poor students raise the quality of their education by almost 30\% over the base level. Increasing spending for the poor so that one-fourth of the expenditure gap closes raises the standard by $7.7 \%$. High-skilled employment rises by $9.9 \%$ and output by $10.7 \%$. Closing the gap by half increases skilled employment and output by $13 \%$ and $22.5 \%$, respectively.

Finally, financial support for poor students' education is more effective in increasing output in a more efficient economy where worker productivity $(\pi)$ is higher, information asymmetry $(\beta)$ and skill mismatch $(n)$ lower. As these factors improve, the poor's incentive to pursue higher education rises. The standard and the ability threshold have to rise less to increase student effort; the same amount of government help move more poor students to higher education

$\left(\frac{\partial s^{*}}{\partial v_{p} \partial \pi}<0, \frac{\partial s^{*}}{\partial v_{p} \partial \beta}<0, \frac{\partial s^{*}}{\partial v_{p} \partial n}<0\right)$.

Table 2: Effects of closing the expenditure gap

\begin{tabular}{lccc}
\hline & $\begin{array}{c}\text { \% change in } \\
\text { standard }\end{array}$ & $\begin{array}{c}\text { \% change in skilled } \\
\text { employment }\end{array}$ & \% change in output \\
\hline Gap closed by $\mathbf{2 5 \%}$ & 7.7 & 9.2 & 10.7 \\
Gap closed by $\mathbf{5 0 \%}$ & 13.0 & 16.9 & 22.5 \\
\hline
\end{tabular}

\section{Conclusion}

Here we develop a model of educational standard determination along the theoretical work carried out by Costrell (1994), Betts (1998) and De Paola and Scoppa (2007). We extend the analysis by including the relationship between inequality in educational opportunities and the optimal standard. Our model implies that setting educational standards as part of a larger education policy requires careful thinking in terms of its effects on the economy. Policymakers willing to determine an output maximizing standard need to consider more factors than those spelled out by these earlier contributions: levels of educational spending by different income groups, share of these groups in the population, skills mismatch in the economy, profit and wage shares, the way an increase in labor productivity is distributed, reservation wage as well as roles of student ability and information asymmetry. High standards are not optimal under severe educational inequality; they lead to lower output when a substantial part of the population cannot access quality education. Optimal standard rises along with better opportunities for low-income students. Therefore, targeted subsidies enhance both distributional and efficiency-related objectives. Other effective policies to extend higher education and to increase poor workers' income are related to the structure of the labor market. Better information between employers and workers and higher labor share in output gains increase reward for effort and lead to more human capital accumulation. 


\section{References}

Akerlof, G.A. (1970), The market for lemons: qualitative uncertainty and the market mechanism, Quarterly Journal of Economics, 84(3): 488-500. doi: 10.2307/1879431

Backes-Gellner, U. and S. Veen (2006), Incentives for Schools, Educational Signals and Labour Market Outcomes, Working Paper, Institute for Strategy and Business Economics, University of Zurich. http://www.isu.uzh.ch/leadinghouse/WorkingPapers/0009_lhwpaper.pdf

Bailey, M.J. and S.M. Dynarski (2011), Changing inequality in US college entry and completion, NBER Working Paper 17633. http://www.nber.org/papers/w17633

Berg, A. and J.D. Ostry (2011), Inequality and Unsustainable Growth: Two Sides of the Same Coin?. IMF Staff Discussion Note 11/08. Washington: International Monetary Fund.

Betts, J. R. (1998), The Impact of Educational Standards on the Level and Distribution of Earnings, The American Economic Review, 88(1), 266-275.

Betts, J.R. and J. Grogger (2003), The impact of grading standards on student achievement, educational attainment, and entry-level earnings, Economics of Education Review, 22(4):343-352. doi: 10.1016/S0272-7757(02)00059-6

Bishop, J. H. (2004), Drinking from the fountain of knowledge: Student incentive to study and learn - externalities, information problems and peer pressure, CAHRS Working Paper \#04-15, Cornell University, NY.

Bishop, J. (2005), High School Exit Examinations: When Do Learning Effects Generalize?, Yearbook of the National Society for the Study of Education, 104(2): 260-288. doi: 10.1111/j.1744-7984.2005.00033.x

Björklund, A. and K.G. Salvanes (2011), Education and Family Background: Mechanisms and Policies, in Handbook of the Economics of Education, ed. by E.A. Hanushek, S. Machin and L. Woessmann, , Elsevier. doi: 10.1016/B978-0-444-53429-3.00003-X

Bonesronning, H. (2004), Do the teachers' grading practices affect student achievement?, Education Economics, 12(2): 151-167.doi: 10.1080/0964529042000239168

Costrell, R. M. (1994), A Simple Model of Educational Standards, American Economic Review, 84(4), 956-971.

De Carvalho Andrade, E. and L.I. De Castro (2011), Tougher Educational Exam Leading to Worse Selection, Economics: The Open-Access, Open-Assessment E-Journal, 5(17). doi: 10.5018/economics-ejournal.ja.2011-17

De Fraja G., T. Oliveira and L. Zanchi (2010), Must Try Harder: Evaluating the Role of Effort in Educational Attainment, Review of Economics and Statistics, 92(3), 577-597. doi: 10.1162/REST a 00013

De Paola M. and V. Scoppa (2007), Returns to Skills, Incentives to Study and Optimal Educational Standards, Journal of Economics, 92(3), 229-262. doi:10.1007/s00712$\underline{0070288-9}$

De Paola, M. and V. Scoppa (2010), A signalling model of school grades under different evaluation systems, Journal of Economics, 101(3):199-212. doi: 10.1007/s00712-010$\underline{0145-0}$

Delaney, L., C. Harmon and C. Redmond (2011), Parental education, grade attainment and 
earnings expectations among university students, Economics of Education Review, 30(6): 1136-1152. doi:10.1016/j.econedurev.2011.04.004.

Easterly, W. (2007), Inequality Does Cause Underdevelopment: Insights from a New Instrument, Journal of Development Economics, 84(2): 755-76. doi: 10.1016/j.jdeveco.2006.11.002

Figlio, D.N. and M.E. Lucas (2004), Do high grading standards affect student performance?, Journal of Public Economics, 88(9-10): 1815- 1834. doi: 10.1016/S0047$\underline{2727(03) 00039-2}$

Giorgio, B. and D. Checchi (2007), Does school tracking affect equality of opportunity? New international evidence, Economic Policy, 22(52): 781-861. doi: 10.1111/j.1468$\underline{0327.2007 .00189 . x}$

Guimaraes, J. and B. Sampaio (2013), Family background and students' achievement on a university entrance exam in Brazil, Education Economics, 21(1): 38-59. doi: $\underline{10.1080 / 09645292.2010 .545528}$

Hanushek, E.A. and L. Wossmann (2007), The Role of Education Quality in Economic Growth, World Bank Policy Research Working Paper 4122. https://openknowledge.worldbank.org/bitstream/handle/10986/7154/wps4122.pdf

Heckman, J. (2008), Schools, Skills, and Synapses, Economic Inquiry, 46(3): 289-324. doi: 10.1111/j.1465-7295.2008.00163.x

Kornrich, S. and F. Furstenberg (2013), Investing in Children: Changes in Parental Spending on Children, 1972-2007, Demography, 50(1): 1-23. doi: 10.1007/s13524-012-0146-4

Lochner, L. and A. Monge-Naranjo (2011), Credit Constraints in Education, NBER Working Papers 17435, Cambridge, Mass.: National Bureau of Economic Research. doi: $\underline{10.3386 / \mathrm{w} 17435}$

Niu, S. and M. Tienda (2013), High School Economic Composition and College Persistence, Research in Higher Education, 54(1): 30-62. doi: 10.1007/s11162-012-9265-4

Reardon, S.F. (2011), The Widening Academic Achievement Gap Between the Rich and the Poor: New Evidence and Possible Explanations, in Whither Opportunity?, ed. by G.J. Duncan and R.J. Murnane, Russell Sage Foundation Press: New York.

Spence, M. (1973), Job market signalling, Quarterly Journal of Economics, 87(3): 355-74. doi: $10.2307 / 1882010$

Williams Shanks, T.R. and C. Robinson (2013), Assets, economic opportunity and toxic stress: A framework for understanding child and educational outcomes, Economics of Education Review, 33: 154-170. doi: 10.1016/j.econedurev.2012.11.002 


\section{Appendix A}

We have to show $e_{i}^{*}<\bar{e}_{i}$ for $a_{i}<a_{2}$ and $e_{i}^{*}>\bar{e}_{i}$ for $a_{i}>a_{2}$. Since the proof is the same for either group, the group subscript or superscript $j$ is omitted. Note that $e_{i}^{*}=\frac{\beta \pi a_{i}(1+n v)}{\gamma}$ is increasing and $\bar{e}_{i}=\frac{s}{a_{i}(1+v)}$ is decreasing in ability; therefore, there can be a unique ability level $a_{i}$ where $e_{i}^{*}$ and $\bar{e}_{i}$ are equal: $e_{i}^{*}=\frac{\beta \pi a_{i}(1+n v)}{\gamma}=\frac{s}{a_{i}(1+v)}=\bar{e}_{i}$

The solution gives $a_{i}=a_{2}$. Then $e_{2}^{*}=\frac{\beta \pi a_{2}(1+n v)}{\gamma}=\bar{e}_{2}=\frac{s}{a_{2}(1+v)}$.

For all $a_{i}<a_{2}, e_{i}^{*}=\frac{\beta \pi a_{i}(1+n v)}{\gamma}$ is smaller than $e_{2}^{*}=\frac{\beta \pi a_{2}(1+n v)}{\gamma}$. Then $e_{i}^{*}$ is also smaller than $\bar{e}_{2}$. On the other hand, for all $a_{i}<a_{2}, \bar{e}_{i}=\frac{s}{a_{i}(1+v)}$ is greater than $\bar{e}_{2}=\frac{s}{a_{2}(1+v)}$. This proves that $\bar{e}_{i}$ is greater than $e_{i}^{*}$ for $a_{i}<a_{2}$.

For all $a_{i}>a_{2}, e_{i}^{*}=\frac{\beta \pi a_{i}(1+n v)}{\gamma}$ is greater than $e_{2}^{*}=\frac{\beta \pi a_{2}(1+n v)}{\gamma}$. Then $e_{i}^{*}$ is also greater than $\bar{e}_{2}$. On the other hand, for all $a_{i}>a_{2}, \bar{e}_{i}=\frac{s}{a_{i}(1+v)}$ is smaller than $\bar{e}_{2}=\frac{s}{a_{2}(1+v)}$. This proves that $e_{i}^{*}$ is greater than $\bar{e}_{i}$ for $a_{i}>a_{2}$.

\section{Appendix B}

We have to show that $a_{1}<a_{2}$ :

$$
\begin{gathered}
\sqrt{\frac{\gamma}{2(1+v)[(1+v)((1-\beta) B(s)-w)+\beta \pi(1+n v) s]} s}<\sqrt{\frac{\gamma s}{\beta \pi(1+v)(1+n v)}} \\
\frac{\gamma s^{2}}{2(1+v)[(1+v)((1-\beta) B(s)-w)+\beta \pi(1+n v) s]}<\frac{\gamma s}{\beta \pi(1+v)(1+n v)} \\
\frac{s}{2[(1+v)((1-\beta) B(s)-w)+\beta \pi(1+n v) s]}<\frac{1}{\beta \pi(1+n v)} \\
\left(\frac{1 / s}{1 / s}\right) \frac{s}{2[(1+v)((1-\beta) B(s)-w)+\beta \pi(1+n v) s]}<\frac{1}{\beta \pi(1+n v)} \\
\frac{1}{(2 / s)(1+v)((1-\beta) B(s)-w)+2 \beta \pi(1+n v)}<\frac{1}{\beta \pi(1+n v)}
\end{gathered}
$$

Since $(2 / s)(1+v)((1-\beta) B(s)-w)>0$, the inequality is satisfied.

\section{Appendix C}

Comparative statics results for the optimal standard $s^{*}$ :

$$
\frac{\partial s^{*}}{\partial \beta}=-\frac{\pi \sqrt{2} \tau w}{(3 \sqrt{2}-4)(\beta \pi+\pi+\rho)^{2}}\left[\frac{\frac{\alpha}{\sqrt{\left(1+v_{p}\right)\left(1+n v_{p}\right)}}+\frac{1-\alpha}{\sqrt{\left(1+v_{r}\right)\left(1+n v_{r}\right)}}}{\alpha \frac{\sqrt{1+n v_{p}}}{\left(1+v_{p}\right)^{3 / 2}}+(1-\alpha) \frac{\sqrt{1+n v_{r}}}{\left(1+v_{r}\right)^{3 / 2}}}\right]<0
$$




$$
\begin{aligned}
& \frac{\partial s^{*}}{\partial \pi}=-\frac{(1+\beta) \sqrt{2} \tau w}{(3 \sqrt{2}-4)(\beta \pi+\pi+\rho)^{2}}\left[\frac{\frac{\alpha}{\sqrt{\left(1+v_{p}\right)\left(1+n v_{p}\right)}}+\frac{1-\alpha}{\sqrt{\left(1+v_{r}\right)\left(1+n v_{r}\right)}}}{\alpha \frac{\sqrt{1+n v_{p}}}{\left(1+v_{p}\right)^{3 / 2}}+(1-\alpha) \frac{\sqrt{1+n v_{r}}}{\left(1+v_{r}\right)^{3 / 2}}}\right]<0 \\
& \frac{\partial s^{*}}{\partial \rho}=-\frac{\sqrt{2} \tau w}{(3 \sqrt{2}-4)(\beta \pi+\pi+\rho)^{2}}\left[\frac{\frac{\alpha}{\sqrt{\left(1+v_{p}\right)\left(1+n v_{p}\right)}}+\frac{1-\alpha}{\sqrt{\left(1+v_{r}\right)\left(1+n v_{r}\right)}}}{\alpha \frac{\sqrt{1+n v_{p}}}{\left(1+v_{p}\right)^{3 / 2}}+(1-\alpha) \frac{\sqrt{1+n v_{r}}}{\left(1+v_{r}\right)^{3 / 2}}}\right]<0 \\
& \frac{\partial s^{*}}{\partial w}=\frac{\sqrt{2} \tau}{(3 \sqrt{2}-4)(\beta \pi+\pi+\rho)}\left[\frac{\frac{\alpha}{\sqrt{\left(1+v_{p}\right)\left(1+n v_{p}\right)}}+\frac{1-\alpha}{\sqrt{\left(1+v_{r}\right)\left(1+n v_{r}\right)}}}{\alpha \frac{\sqrt{1+n v_{p}}}{\left(1+v_{p}\right)^{3 / 2}}+(1-\alpha) \frac{\sqrt{1+n v_{r}}}{\left(1+v_{r}\right)^{3 / 2}}}\right]>0 \\
& \frac{\partial s^{*}}{\partial \alpha}=\frac{\sqrt{2} \tau w}{(3 \sqrt{2}-4)(\beta \pi+\pi+\rho)} \frac{\left(\frac{\frac{1+n v_{r}}{1+v_{r}}-\frac{1+n v_{p}}{1+v_{p}}}{\sqrt{\left(1+v_{p}\right)\left(1+n v_{p}\right)\left(1+v_{r}\right)\left(1+n v_{r}\right)}}\right)}{\left(\alpha \frac{\sqrt{1+n v_{p}}}{\left(1+v_{p}\right)^{3 / 2}}+(1-\alpha) \frac{\sqrt{1+n v_{r}}}{\left(1+v_{r}\right)^{3 / 2}}\right)^{2}}<0
\end{aligned}
$$

Since $\frac{1+n v_{p}}{1+v_{p}}>\frac{1+n v_{r}}{1+v_{r}}, \frac{\partial s^{*}}{\partial \alpha}$ is negative.

$\frac{\partial s^{*}}{\partial n}=\frac{w}{\sqrt{2}(3 \sqrt{2} 4)(++)} x$

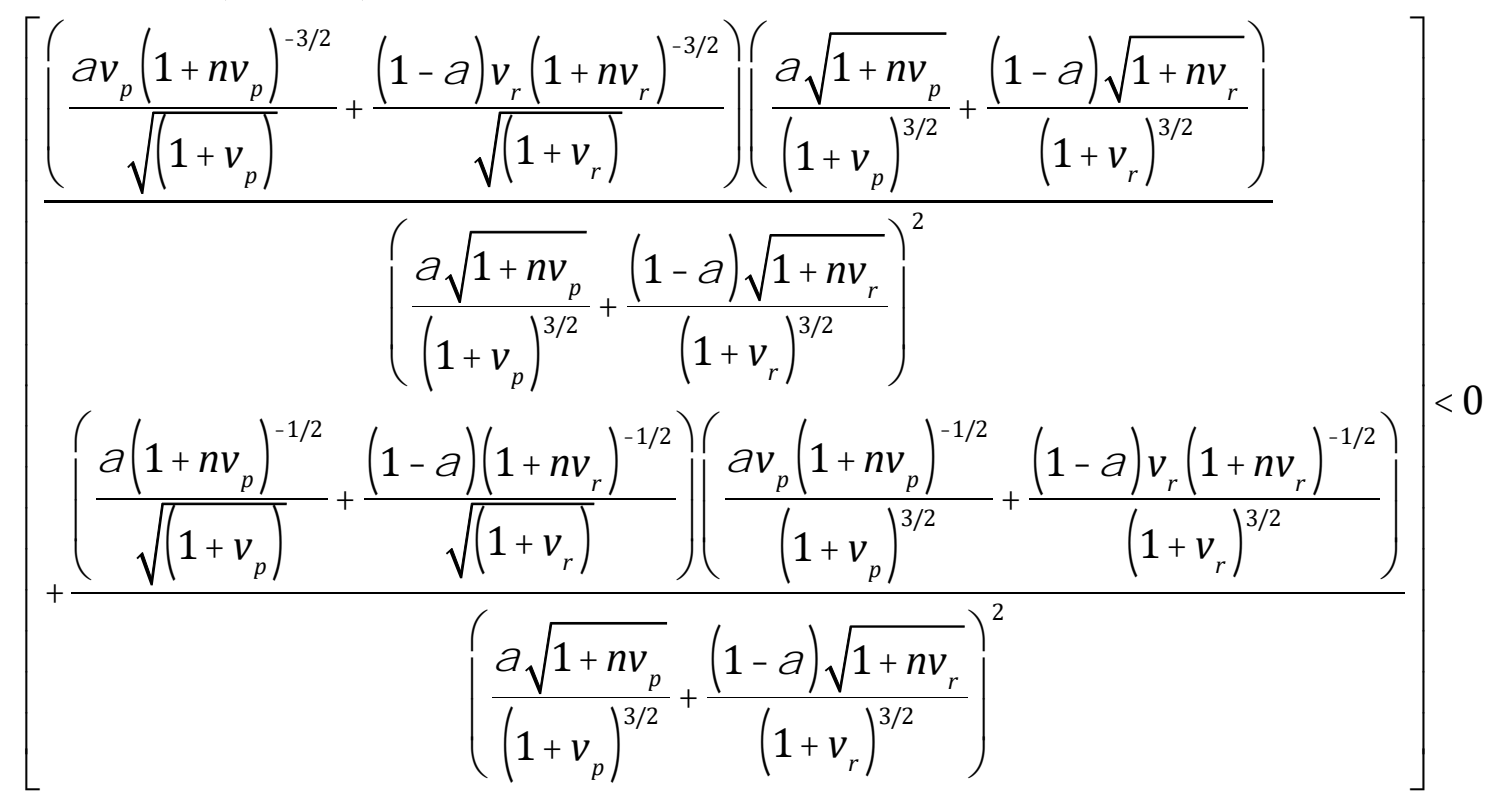


The effect of the educational spending on the optimal standard is given by $\frac{\partial s^{*}}{\partial M_{j}}$ which can be written as $\frac{\partial s^{*}}{\partial M_{j}}=\frac{\partial s^{*}}{\partial v_{j}} \frac{\partial v_{j}}{\partial M_{j}}=\frac{k l}{M_{j}^{1-k}} \frac{\partial s^{*}}{\partial v_{j}}$. Then $\frac{\partial s^{*}}{\partial M_{j}}$ will have the same sign as $\frac{\partial s^{*}}{\partial v_{j}}$ because $\frac{k l}{M_{j}^{1-k}}$ is positive.

To calculate $\frac{\partial s^{*}}{\partial v_{p}}$ we first manipulate the equation for $s^{*}$ in the following way $s^{*}$

$$
\begin{aligned}
& =\frac{\sqrt{2} \tau w}{(3 \sqrt{2}-4)(\beta \pi+\pi+\rho)}\left[\frac{\frac{\alpha}{\sqrt{\left(1+v_{p}\right)\left(1+n v_{p}\right)}}+\frac{1-\alpha}{\sqrt{\left(1+v_{r}\right)\left(1+n v_{r}\right)}}}{\alpha \frac{\sqrt{1+n v_{p}}}{\left(1+v_{p}\right)^{3 / 2}}+(1-\alpha) \frac{\sqrt{1+n v_{r}}}{\left(1+v_{r}\right)^{3 / 2}}}\right]\left(\frac{\sqrt{\left(1+v_{p}\right)\left(1+n v_{p}\right)}}{\alpha}\right) \\
& s^{*}=\frac{\sqrt{2} \tau w}{(3 \sqrt{2}-4)(\beta \pi+\pi+\rho)}\left[\frac{1+\left(\frac{1-\alpha}{\alpha}\right) \frac{\sqrt{\left(1+v_{p}\right)\left(1+n v_{p}\right)}}{\sqrt{\left(1+v_{r}\right)\left(1+n v_{r}\right)}}}{\left(\frac{1+n v_{p}}{1+v_{p}}\right)+\left(\frac{1-\alpha}{\alpha}\right) \frac{\sqrt{\left(1+n v_{r}\right)\left(1+v_{p}\right)\left(1+n v_{p}\right)}}{\left(1+v_{r}\right)^{3 / 2}}}\right]
\end{aligned}
$$

Let $\varphi=\frac{\sqrt{2} \tau w}{(3 \sqrt{2}-4)(\beta \pi+\pi+\rho)}$ and $\vartheta=\left(\left(\frac{1+n v_{p}}{1+v_{p}}\right)+\left(\frac{1-\alpha}{\alpha}\right) \frac{\sqrt{\left(1+n v_{r}\right)\left(1+v_{p}\right)\left(1+n v_{p}\right)}}{\left(1+v_{r}\right)^{3 / 2}}\right)$

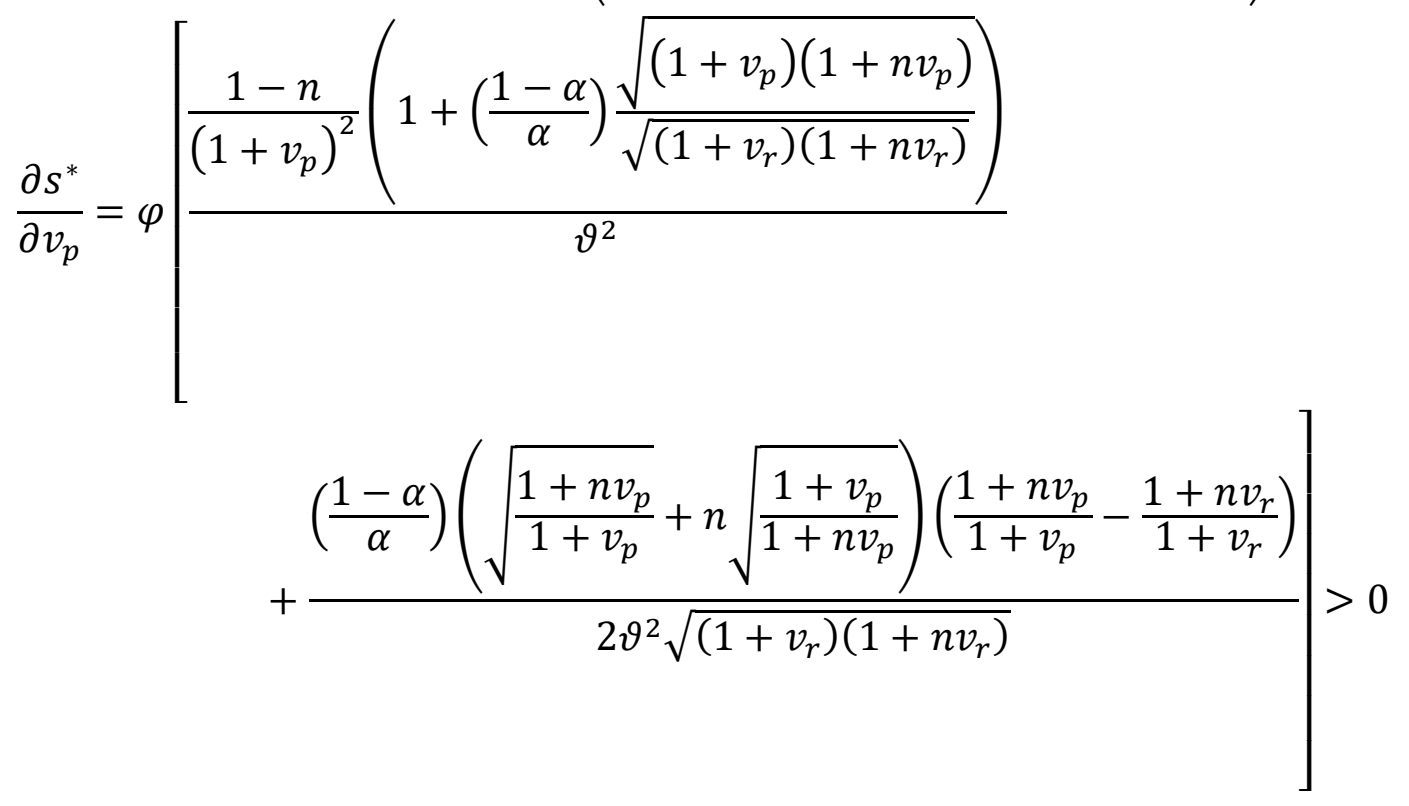

We can write $\left(\frac{1+n v_{p}}{1+v_{p}}-\frac{1+n v_{r}}{1+v_{r}}\right)$ as $\left(\frac{\left(1+n v_{p}\right)\left(1+v_{r}\right)-\left(1+v_{p}\right)\left(1+n v_{r}\right)}{\left(1+v_{p}\right)\left(1+v_{r}\right)}\right)=\frac{(1-n)\left(v_{r}-v_{p}\right)}{\left(1+v_{p}\right)\left(1+v_{r}\right)}$. Since $v_{r}>$ $v_{p}, \frac{\partial s^{*}}{\partial v_{p}}$ is positive. Then $\frac{\partial s^{*}}{\partial M_{p}}=\frac{k l}{M_{p}^{1-k}} \frac{\partial s^{*}}{\partial v_{j}}>0$.

To calculate $\frac{\partial s^{*}}{\partial M_{r}}$ and $\frac{\partial s^{*}}{\partial v_{r}}$, we proceed similarly 


$$
\begin{gathered}
s^{*}=\varphi\left[\frac{\frac{\alpha}{\sqrt{\left(1+v_{p}\right)\left(1+n v_{p}\right)}}+\frac{1-\alpha}{\sqrt{\left(1+v_{r}\right)\left(1+n v_{r}\right)}}}{\alpha \frac{\sqrt{1+n v_{p}}}{\left(1+v_{p}\right)^{3 / 2}}+(1-\alpha) \frac{\sqrt{1+n v_{r}}}{\left(1+v_{r}\right)^{3 / 2}}}\right]\left(\frac{\frac{\sqrt{\left(1+v_{r}\right)\left(1+n v_{r}\right)}}{1-\alpha}}{\frac{\sqrt{\left(1+v_{r}\right)\left(1+n v_{r}\right)}}{1-\alpha}}\right) \\
s^{*}=\varphi\left[\frac{1+\left(\frac{\alpha}{1-\alpha}\right) \frac{\sqrt{\left(1+v_{r}\right)\left(1+n v_{r}\right)}}{\sqrt{\left(1+v_{p}\right)\left(1+n v_{p}\right)}}}{\left(\frac{1+n v_{r}}{1+v_{r}}\right)+\left(\frac{\alpha}{1-\alpha}\right) \frac{\sqrt{\left(1+n v_{p}\right)\left(1+v_{r}\right)\left(1+n v_{r}\right)}}{\left(1+v_{p}\right)^{3 / 2}}}\right]
\end{gathered}
$$

$$
\begin{aligned}
& \text { Let }=\left(\left(\frac{1+n v_{r}}{1+v_{r}}\right)+\left(\frac{\alpha}{1-\alpha}\right) \frac{\sqrt{\left(1+n v_{p}\right)\left(1+v_{r}\right)\left(1+n v_{r}\right)}}{\left(1+v_{p}\right)^{3 / 2}}\right) \\
& \frac{\partial s^{*}}{\partial v_{r}}=\left(1+\left(\frac{1-\alpha}{\alpha}\right) \frac{\sqrt{\left(1+v_{p}\right)\left(1+n v_{p}\right)}}{\sqrt{\left(1+v_{r}\right)\left(1+n v_{r}\right)}}\right. \\
& \left.-\frac{1}{2}\left(1+\frac{n+n v_{r}}{1+n v_{r}}\right)\left(\frac{v_{r}-v_{p}}{1+v_{p}}\right)\right)\left(\frac{\varphi(1-n)\left(\frac{\alpha}{1-\alpha}\right) \frac{\left(1+n v_{r}\right)^{1 / 2}}{\left(1+v_{r}\right)^{3 / 2}}}{\omega^{2} \sqrt{\left(1+v_{p}\right)\left(1+n v_{p}\right)}}\right)
\end{aligned}
$$

$\frac{\partial s^{*}}{\partial v_{r}}$ and $\frac{\partial s^{*}}{\partial M_{r}}$ are positive unless education inequality $\left(v_{r}-v_{p}\right)$ exceeds the threshold given by

$$
\frac{\left(1+v_{p}\right)\left(1+\left(\frac{1-\alpha}{\alpha}\right) \frac{\sqrt{\left(1+v_{p}\right)\left(1+n v_{p}\right)}}{\sqrt{\left(1+v_{r}\right)\left(1+n v_{r}\right)}}\right)}{2\left(1+\frac{n+n v_{r}}{1+n v_{r}}\right)}
$$

Simulations show that $\frac{\partial s^{*}}{\partial v_{r}}$ and $\frac{\partial s^{*}}{\partial M_{r}}$ turn negative only under extreme inequality in education. At this inequality level, almost all rich students pass the standard. Additional expenditure on the rich has almost no effect because of decreasing returns to spending. On the other hand, there are many higher ability poor students who cannot go to college. Benefit on output of increasing the number of poor but brighter students in high-skilled employment outweighs the negative effect on output (via less effort) of a lower standard.

\section{Appendix D}

Human capital of a worker is observable when she applies for a job under perfect information. A student $i$ exerts effort $e_{i}^{*}=\frac{\pi\left(1+n v_{j}\right) a_{i}}{\gamma}$ if her utility of being a skilled worker, 
$\pi e_{i}^{*} a_{i}\left(1+n v_{j}\right)-\frac{\gamma\left(e_{i}^{*}\right)^{2}}{2}$, exceeds the utility of low-skill wage, $w$. High-skill wage truly reflects her contribution since there is no observation period $(\beta=1)$. Otherwise she shows no effort. $e_{i}^{*}$ is the solution to the maximization of a skilled worker's utility function. Let's say student $i$ is indifferent between the two options:

$\pi e_{i}^{*} a_{i}\left(1+n v_{j}\right)-\frac{\gamma\left(e_{i}^{*}\right)^{2}}{2}=w$ or $\pi\left(\frac{\pi\left(1+n v_{j}\right) a_{i}}{\gamma}\right) a_{i}\left(1+n v_{j}\right)-\frac{\gamma\left(\frac{\pi\left(1+n v_{j}\right) a_{i}}{\gamma}\right)^{2}}{2}=w$

Then students with ability greater than $a_{i}=\frac{\sqrt{2 \gamma w}}{\pi\left(1+n v_{j}\right)}$ exert effort and work in high-skill sector.

When information is not perfect and there is not a standard to screen workers, employers will not pay a wage higher than $w$ in the observation period $(1-\beta)$. We assume that some minimum level of human capital is necessary to produce in high-skilled jobs. A worker who exerted no effort at school cannot be productive in high-skill sector; any wage greater than $w$ in the trial period will attract such workers and lower profits.

Student $i$ exerts effort $e_{i}^{*}=\frac{\beta \pi\left(1+n v_{j}\right) a_{i}}{\gamma}$ if $(1-\beta) w+\beta \pi e_{i}^{*} a_{i}\left(1+n v_{j}\right)-\frac{\gamma\left(e_{i}^{*}\right)^{2}}{2} \geq w$. Let's say student $i$ is indifferent between the two jobs:

$(1-\beta) w+\beta \pi\left(\frac{\beta \pi\left(1+n v_{j}\right) a_{i}}{\gamma}\right) a_{i}\left(1+n v_{j}\right)-\frac{\gamma\left(\frac{\beta \pi\left(1+n v_{j}\right) a_{i}}{\gamma}\right)^{2}}{2}=w$.

Then students with ability greater than $a_{i}=\frac{\sqrt{2 \gamma w}}{\pi\left(1+n v_{j}\right) \sqrt{\beta}}$ prefer spending effort. 